\title{
Prevalence of Medical Humanities Teaching in Medical Schools: Review of Curricula in the United States, Canada, and the United Kingdom
}

\author{
Jeremy Howick ${ }^{1}$, Lunan Zhao $^{2}$, Brenna McKaig ${ }^{3}$, RAFFAELLA CAMPANER ${ }^{4}$, \\ Alessandro Rosa ${ }^{5}$, Jason $\mathrm{Oke}^{6}$, and Dien $\mathrm{Ho}^{3}$ \\ ${ }^{1}$ Oxford University \\ ${ }^{2}$ University of Toronto \\ ${ }^{3} \mathrm{MCPHS}$ \\ ${ }^{4}$ Affiliation not available \\ ${ }^{5}$ University of Bologna \\ ${ }^{6}$ University of Oxford
}

January 15, 2021

\begin{abstract}
Rationale and Objectives Medical humanities are becoming increasingly popular, required, and recognized as positively impacting medical education and medical practice. However, the extent of medical humanities teaching in medical schools is largely unknown. We aimed to review medical school curricula in Canada, the UK, and the US. Our secondary objective was to compare the inclusion of medical humanities in the curricula with rankings of medical schools. Methods We searched the curriculum websites of all accredited medical schools in Canada, the UK, and the US to check which medical humanities topics were taught, and whether they were mandatory or optional. We then noted rankings both by Times Higher Education and U.S. News and World Report and calculated the average rank. We formally explored whether there was an association between average medical school ranking and medical humanities offerings using Spearman's correlation and inverse variance weighting meta-analysis. Results We identified 18 accredited medical school programmes in Canada, 41 in the UK, and 156 in the US. Of these, 9 (56\%) in Canada, 34 (73\%) in the UK and 124 (79\%) in the US offered at least one medical humanity that was not ethics. The most common medical humanities were Unspecified Medical Humanities, History, and Literature (Canada), Sociology and Social Medicine, Unspecified Medical Humanities, and Art (UK), and Unspecified Medical Humanities, Literature, and History (US). There was a negative relationship between the ranking of the medical school and whether they offered medical humanities. Conclusions The extent and content of medical humanities offerings at accredited medical schools in Canada, the UK, and the US varies. The quality of our analysis was limited by the data provided on the Universities' curriculum websites. Given the potential for medical humanities to improve medical education and medical practice, this variation should be investigated further.
\end{abstract}

\section{Hosted file}

HOWICK Medical Humanities in Medical Schools Full Draft Final.pdf available at https:// authorea. com/users/389644/articles/504226-prevalence-of-medical-humanities-teaching-inmedical-schools-review-of-curricula-in-the-united-states-canada-and-the-united-kingdom

\section{Hosted file}

Table 1.pdf available at https://authorea.com/users/389644/articles/504226-prevalence-of- 
medical-humanities-teaching-in-medical-schools-review-of-curricula-in-the-united-statescanada-and-the-united-kingdom

\section{Hosted file}

Table 2.pdf available at https://authorea.com/users/389644/articles/504226-prevalence-ofmedical-humanities-teaching-in-medical-schools-review-of-curricula-in-the-united-statescanada-and-the-united-kingdom

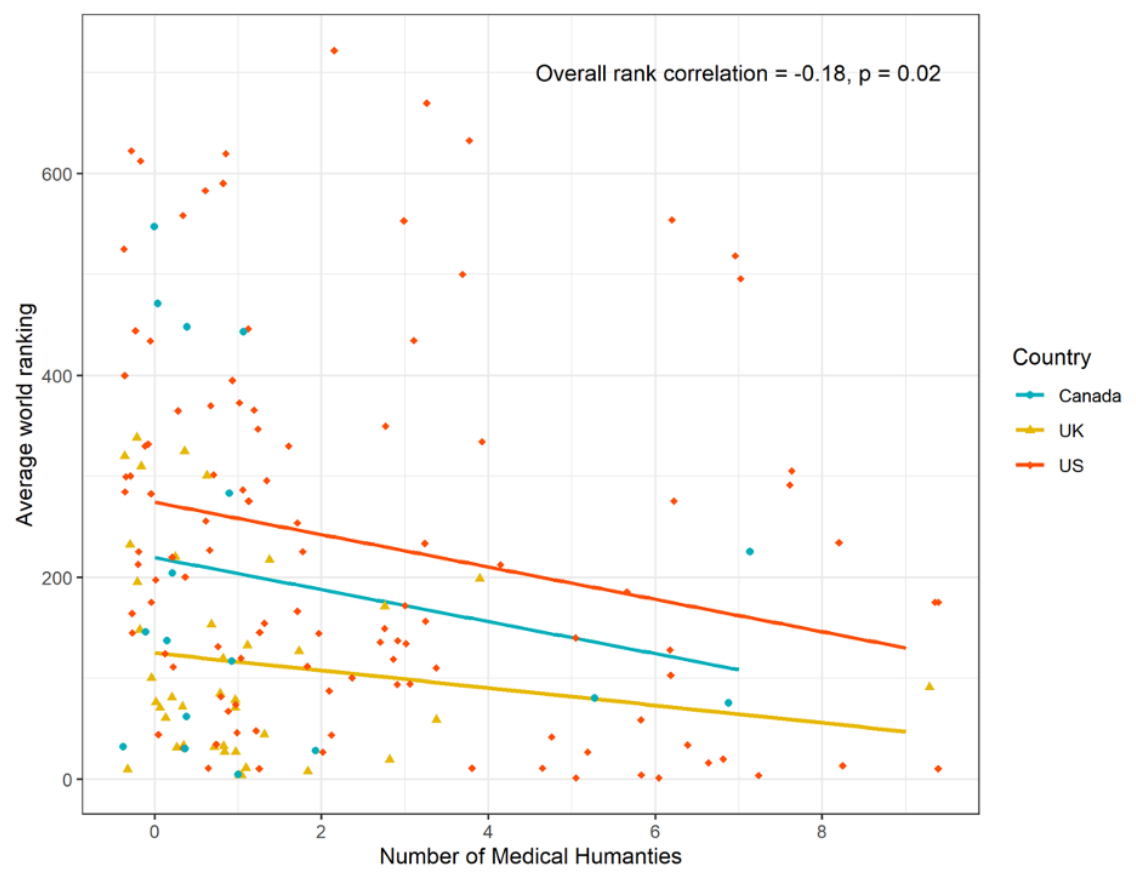




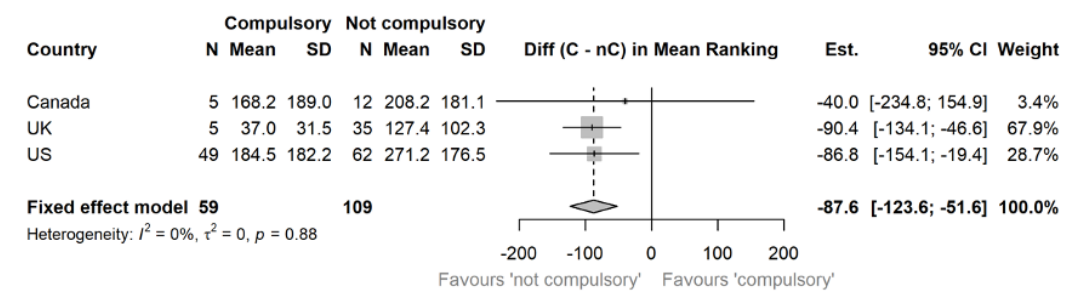

